\title{
BMJ A model for scale up of family health open innovations in low-income and middle- income settings: a mixed methods study
}

\author{
Elizabeth H Bradley, ${ }^{1}$ Leslie A Curry, ${ }^{2}$ Lauren A Taylor, ${ }^{1}$ Sarah Wood Pallas, ${ }^{2}$ \\ Kristina Talbert-Slagle, ${ }^{2}$ Christina Yuan, ${ }^{2}$ Ashley Fox, ${ }^{2}$ Dilpreet Minhas, ${ }^{1}$ \\ Dana Karen Ciccone, ${ }^{1}$ David Berg, ${ }^{3}$ Rafael Pérez-Escamilla ${ }^{2}$
}

To cite: Bradley EH, Curry LA, Taylor LA, et al. A model for scale up of family health innovations in lowincome and middle-income settings: a mixed methods study. BMJ Open 2012;2: e000987. doi:10.1136/ bmjopen-2012-000987

- Prepublication history and additional material for this paper are available online. To view these files please visit the journal online (http:// dx.doi.org/10.1136/bmjopen2012-000987)

Received 3 February 2012 Accepted 20 July 2012

This final article is available for use under the terms of the Creative Commons Attribution Non-Commercial 2.0 Licence; see http://bmjopen.bmj.com

\footnotetext{
${ }^{1}$ Yale Global Health Leadership Institute, Yale University, New Haven, Connecticut, USA

${ }^{2}$ Yale School of Public Health, New Haven, Connecticut, USA

${ }^{3}$ Yale School of Medicine, New Haven, Connecticut, USA

Correspondence to Dr Elizabeth H Bradley; elizabeth.bradley@yale.edu
}

\section{ABSTRACT}

Background: Many family health innovations that have been shown to be both efficacious and cost-effective fail to scale up for widespread use particularly in lowincome and middle-income countries (LMIC). Although individual cases of successful scale-up, in which widespread take up occurs, have been described, we lack an integrated and practical model of scale-up that may be applicable to a wide range of public health innovations in LMIC.

Objective: To develop an integrated and practical model of scale-up that synthesises experiences of family health programmes in LMICs.

Data sources: We conducted a mixed methods study that included in-depth interviews with 33 key informants and a systematic review of peer-reviewed and grey literature from 11 electronic databases and 20 global health agency web sites.

Study eligibility criteria, participants and interventions: We included key informants and studies that reported on the scale up of several family health innovations including Depo-Provera as an example of a product innovation, exclusive breastfeeding as an example of a health behaviour innovation, community health workers (CHWs) as an example of an organisational innovation and social marketing as an example of a business model innovation. Key informants were drawn from nongovernmental, government and international organisations using snowball sampling. An article was excluded if the article: did not meet the study's definition of the innovation; did not address dissemination, diffusion, scale up or sustainability of the innovation; did not address low-income or middleincome countries; was superficial in its discussion and/ or did not provide empirical evidence about scale-up of the innovation; was not available online in full text; or was not available in English, French, Spanish or Portuguese, resulting in a final sample of 41 peerreviewed articles and 30 grey literature sources.

Study appraisal and synthesis methods: We used the constant comparative method of qualitative data analysis to extract recurrent themes from the interviews, and we integrated these themes with findings from the literature review to generate the proposed model of scale-up. For the systematic review,

\section{ARTICLE SUMMARY}

\section{Article focus}

- To develop an integrated and practical model of scale up that synthesises experiences of family health programmes in low-income and middle-income countries (LMICS).

- The resulting model-the AIDED modelincludes five non-linear, interrelated components: (1) assess the landscape, (2) innovate to fit user receptivity, (3) develop support, (4) engage user groups and (5) devolve efforts for spreading innovation.

\section{Key messages}

- Failure to scale up may be attributable to insufficient assessment of user groups in context, lack of fit of the innovation with user receptivity, inability to address resistance from stakeholders and inadequate engagement with user groups.

- Successful scale-up occurs within a complex adaptive system, characterised by interdependent parts, multiple feedback loops and several potential paths to achieve intended outcomes.

- Flexible strategies of assessment, innovation, development, engagement and devolution are required to enable effective change in the use of family health innovations in low-income and middle-income countries.

screening was conducted independently by two team members to ensure consistent application of the predetermined exclusion criteria. Data extraction from the final sample of peer-reviewed and grey literature was conducted independently by two team members using a pre-established data extraction form to list the enabling factors and barriers to dissemination, diffusion, scale up and sustainability.

Results: The resulting model-the AIDED modelincludes five non-linear, interrelated components: (1) assess the landscape, (2) innovate to fit user receptivity, (3) develop support, (4) engage user groups and (5) devolve efforts for spreading innovation. Our findings suggest that successful scaleup occurs within a complex adaptive system, 


\section{ARTICLE SUMMARY}

Strengths and limitations of this study

- The inductive approach used to construct the AIDED model did not allow for simultaneous empirical testing of the model. Future research is needed to validate the AIDED model in new contexts other than those described by our key informants.

- Additionally, the literature may have publication bias in which negative studies are under-represented, and interviews may have social desirability bias, in which participants may have misrepresented their experiences in order to provide desirable answers. Nevertheless, we did find cases of unsuccessful scale-up in the literature, and we probed intentionally to elicit both positive and negative experiences from key informants in order to minimise bias.

- The AIDED model did not address long-term sustained use of innovations that are successfully scaled up. This will require further research to identify lessons learned based on contrasting levels of success sustaining the scaled-up innovations in different settings.

characterised by interdependent parts, multiple feedback loops and several potential paths to achieve intended outcomes. Failure to scale up may be attributable to insufficient assessment of user groups in context, lack of fit of the innovation with user receptivity, inability to address resistance from stakeholders and inadequate engagement with user groups.

Limitations: The inductive approach used to construct the AIDED model did not allow for simultaneous empirical testing of the model. Furthermore, the literature may have publication bias in which negative studies are under-represented, although we did find examples of unsuccessful scale-up. Last, the AIDED model did not address long-term, sustained use of innovations that are successfully scaled up, which would require longer-term follow-up than is common in the literature.

Conclusions and implications of key findings: Flexible strategies of assessment, innovation, development, engagement and devolution are required to enable effective change in the use of family health innovations in LMIC.

\section{INTRODUCTION}

Many family health innovations that have been shown to be both efficacious and cost-effective fail to scale up for widespread use particularly in low-income and middle-income countries (LMIC). As of 2008, only $45 \%$ of married women in LMIC were using modern contraception and only $5 \%$ were using injectables, ${ }^{1}$ rates of exclusive breastfeeding for the first 6 months of life are reportedly at about $38 \%$ in LMIC, ${ }^{2}$ and much of Africa lacks potentially beneficial community health worker programmes. ${ }^{3}$ Such limited use of these family health efforts persists despite ample evidence of their health benefits and cost-effectiveness.

Although individual case studies of successful scale-up have been documented, we lack an integrated, practical model that synthesises scale-up experiences of family health programmes in LMIC. Existing frameworks have identified factors that may influence scale-up, ${ }^{4-7}$ including features of the innovation, the potential adopters and the environment in which scale-up occurs. Nevertheless, these broad domains provide limited guidance on the mechanisms of scale-up, which are essential for guiding effective scale-up efforts in family health.

Accordingly, we sought to synthesise the evidence from key informant experiences as well as peer-reviewed and grey literature to produce a practical model of scale-up. For the purposes of our analysis, we refer to innovation as the use of products, practices or approaches that, for the user, are new. We used Depo-Provera as an example of a product innovation, exclusive breastfeeding as an example of a health behaviour innovation, community health workers (CHWs) as an example of an organisational innovation and social marketing as an example of business model innovation. Although these interventions have existed in some communities for decades, we consider them innovations in contexts and communities where they have not been used previously and are therefore new. These sample innovations provided lenses through which to examine scale-up processes in family health in LMIC.

\section{METHODS}

\section{Study design and sample}

We conducted a mixed methods study that included in-depth interviews and a systematic review of peerreviewed and grey literature. We chose to include a qualitative approach because this method is well suited for studying complex and nuanced social processes ${ }^{8} 9$ and for generating novel insights ${ }^{81011}$ through the use of inductive approaches.

\section{In-depth interviews}

We conducted in-depth interviews with 33 key informants who had a broad range of experiences with scale-up of the selected family health innovations in LMIC. As appropriate for theory development, we used purposeful sampling in which one seeks key informants who have knowledge about and will discuss the phenomenon of inquiry. ${ }^{8}$ We therefore sought informants with expertise in the different innovation types (Depo-Provera, breastfeeding, CHWs and social marketing), with experience at different levels (front-line implementation, policy formulation, funding), in different geographical regions (sub-Saharan Africa, Middle East, Latin America and South Asia), and working in different types of organisations and agencies (government, non-governmental organisations and foundations, United Nations, private sector and universities). We developed the purposeful sample based on relevant peer-reviewed or grey literature, our team's professional networks and the Bill \& Melinda Gates Foundation (BMGF) staff, who had launched major initiatives in family health. We then employed snowball sampling ${ }^{8}$ to enrol additional interviewees until we achieved theoretical saturation, ${ }^{8}{ }^{11}$ that is, until 
successive interviews produced no new concepts, which occurred with 33 interviews. Ultimately, 15 of the 33 people interviewed had associations with the BMGF, although these individuals represented diverse professional backgrounds and relayed experiences that preceded their current role at the BMGF. Interviews were conducted by research team members experienced in qualitative interviewing; two researchers with complementary backgrounds conducted each interview using a standard interview guide (figure 1) either in person or via telephone. The study was reviewed by the Yale Human Subjects Committee (IRB \# 00000594) and granted an exemption under 45 CFR 46.101(b) (2).

We used the constant comparison method ${ }^{811}$ to classify key concepts, expanding and refining properties of the codes with a review of successive transcripts. We reconciled differences in coding through consensus and finalised a comprehensive code structure, which was systematically applied to all transcripts. We used ATLAS.ti Scientific Software, V.6.1, to facilitate organisation, analysis and retrieval of data.

To improve the trustworthiness and reliability of the findings, we employed several methods recommended by experts in qualitative research. ${ }^{8}$ These included tape-recording interviews after consent, using a team of five data coders and analysts who reflected different disciplines, and retaining an audit trail of methods and coding decisions throughout the analysis. For a subset of key informants, we used participant confirmation ${ }^{8} 12$ and incorporated their additional insights from review of the initial findings. Additionally, after the interview and literature review data were synthesised, we conducted respondent validation. ${ }^{13}$ In this process, findings from the in-depth interviews and literature synthesis were shared with study participants to provide feedback; these reactions were addressed and accounted for in the analysis.

\section{Literature review}

We conducted a systematic review of peer-reviewed and grey literature for each of the selected innovations. We included studies conducted in middle-income countries in the review because many countries that are today middle income (eg, India, Brazil) were low income in the past. For each innovation, we searched for peer-reviewed literature in 11 electronic databases (MEDLINE, CINAHL, EMBASE, Web of Knowledge, PsycINFO, Global Health, EconLit, Social Sciences Citation Index, International Bibliography of Social Sciences, Social Services Abstracts and Sociological Abstracts), including any literature published since the earliest date indexed in each database up to 2010. In addition, we searched the websites of 20 leading global health donors, implementers and technical agencies to identify relevant grey literature (WHO, United Nations Children's Fund, United Nations Development Programme, United Nations Population Fund, the World Bank, the African Development Bank, the Inter-American Development Bank, the Asian Development Bank, United States Agency for International Development, Canadian International Development Agency, Department for International Development, Swedish International Development Coorporation Agency, German Agency for International Cooperation, the Global Fund to Fight AIDS, Tuberculosis and Malaria, CARE, GAIN, Family Health International, Partners in Health, Management Sciences for Health and John Snow, Inc.). All searches used a standard set of search terms related to dissemination, diffusion, scale-up and sustainability, and a tailored set of search terms specific to the innovation.

1. Let's start by having you describe your role in implementing this intervention. What was your role and how long were you involved?

2. We are interested in your experience with scaling the intervention. What was the process, from implementation to scale-up of the intervention? Walk me through that.

- What was the goal?

- How did you first approach addressing the issue and implementing the intervention?

- What were the key components of the process?

- Did you come to the process with any pre-conceived ideas about how you would accomplish the task? Can you describe those?

- How did you/are you measuring success?

3. What kinds of challenges came up and how did you handle those?

4. Looking back, is there anything that might have been done differently?

5. Is there anything else we should have asked to help us understand your experience with the intervention and process of implementation and scale-up better?

Figure 1 Discussion guide used in key informant interviews. 
For the peer-reviewed literature, we screened the abstracts of all search results and screened the full text of those articles retained following abstract screening. Screening was conducted independently by two team members to ensure consistent application of the predetermined exclusion criteria. An article was excluded if it did not meet the study's definition of the innovation; if it did not address dissemination, diffusion, scale up or sustainability of the innovation; if it did not address lowincome or middle-income countries; if it was superficial in its discussion and/or did not provide empirical evidence about scale up of the innovation; if the full text of the article was not available online; or if the article was not available in English, French, Spanish or Portuguese.

Grey literature searches included any documents available via the organisation's web site on the February 2011 search dates. Owing to the large volume of hits generated from these web site searches, the titles of all hits were screened first. If a document appeared relevant on the basis of its title, the full text was reviewed using the same exclusion criteria as applied to the peer-reviewed literature.

Data extraction from the final sample of peer-reviewed and grey literature was conducted independently by two research team members using a pre-established data extraction form. The extraction form was used to list the enabling factors and barriers to dissemination, diffusion, scale up and sustainability. Disagreements that occurred during the review in application of the exclusion criteria or in data extraction were resolved through negotiated consensus among the researchers conducting the review.

The resulting enabling factors and barriers found in the literature for each innovation were then mapped to the five AIDED model components to determine the degree of support in the empirical literature for the scale-up process captured in the AIDED model. All authors reviewed the mapping, which was achieved through negotiated consensus and is illustrated in the appendix, tables A1-A8.

\section{RESULTS}

\section{Description of samples}

We interviewed a total of 33 key informants (table 1). Our search of peer-reviewed literature returned 1446 unique articles, of which 41 were retained for data extraction based on our review criteria; 4 additional papers not identified through the electronic search were obtained from the authors' files (figure 2). Additionally, our search of the grey literature returned 30 unique sources for data extraction (table 2). The full list of references reviewed and an example of a full electronic search strategy, for community health worker literature, are included in the appendix.

\section{AIDED model}

Analysis of in-depth interview data and the synthesis of the peer-reviewed and grey literature revealed five

\begin{tabular}{lll}
\multicolumn{3}{l}{ Table 1 Characteristics of key informants } \\
\hline Characteristic & Number & $\%$ \\
\hline Area of expertise & & \\
$\quad$ Family planning (Depo-Provera) & 7 & 21.2 \\
$\quad$ Social marketing & 6 & 18.2 \\
Policy making & 6 & 18.2 \\
Community health worker approaches & 5 & 15.2 \\
$\quad$ General & 5 & 15.2 \\
$\quad$ Breastfeeding & 4 & 12.1 \\
Affiliation & & \\
$\quad$ Nongovernmental organisation & 20 & 60.6 \\
$\quad$ Government & 4 & 12.1 \\
$\quad$ United Nations agency & 3 & 9.1 \\
$\quad$ Consultancy & 3 & 9.1 \\
$\quad$ Academic & 3 & 9.1 \\
Disciplinary background & & \\
$\quad$ Maternal and child health & 7 & 21.2 \\
$\quad$ Health systems research and & 6 & 18.2 \\
programmes & & \\
$\quad$ Health policy & 5 & 15.2 \\
$\quad$ International development and & 4 & 12.1 \\
economics & & \\
$\quad$ Epidemiology/medicine & 3 & 9.1 \\
$\quad$ Reproductive health & 3 & 9.1 \\
$\quad$ Anthropology & 2 & 6.1 \\
$\quad$ Health communications & 2 & 6.1 \\
Management & 1 & 3.0 \\
\hline
\end{tabular}

interrelated components of the scale-up process: assess the landscape, innovate to fit user receptivity, develop support, engage with user groups and devolve efforts for spreading the innovation, which together comprise the AIDED model (figure 3). The data highlighted the complexity and non-linearity of the process, which included multiple feedback loops. Key informants nonetheless indicated that donors and implementers rarely appreciated this complexity:

There's a lot of magical thinking about what this 'pilot project' or 'proof of concept' will do because it's not very real in terms of the stakes necessary to actually sustain for impact and scale. (Interview \#3)

\section{Assess the landscape}

The first component involved obtaining a precise understanding of the receptivity of the user groups and of the environmental context of the user groups. Key informants suggested that a primary limitation of scale-up efforts was poor understanding of what communities wanted and what made them receptive to the innovation; multiple studies ${ }^{14}{ }^{15}$ highlighted the importance of conducting an in-depth assessment prior to launching dissemination efforts.

In public health, there is often a lot of confusion between the need and the demand for innovations. There is a tendency to approach the idea with, 'okay, if I look at the incidence of this particular disease and I 
Electronic Database Search

( $\mathrm{n}=1,446$ unique articles after removing duplicates)

Number of articles identified in each database

- MEDLINE $(n=640)$

- $\operatorname{CINAHL}(n=114)$

- Scopus EMBASE $(n=717)$

- PsycINFO $(n=51)$

- Global Health $(n=176)$
- Web of Knowledge $(n=410)$

- EconLit $(n=16)$

- Social Sciences Citation Index, International Bibliography of the Social Sciences, Social Services Abstracts, Sociological Abstracts $(n=147)$

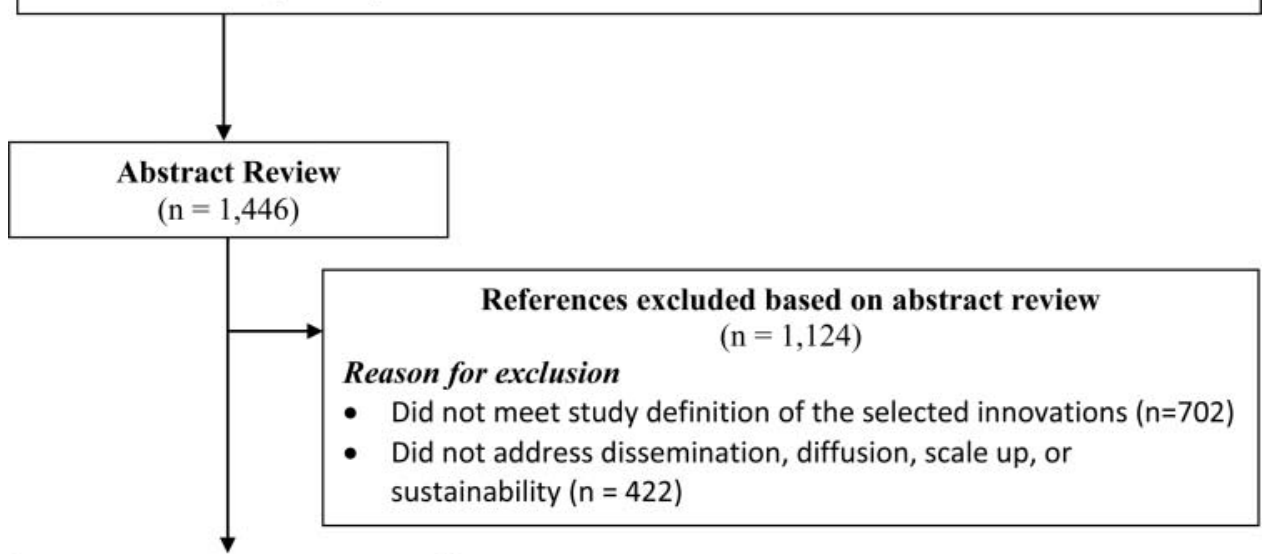

Full Text Screening $(\mathrm{n}=322)$

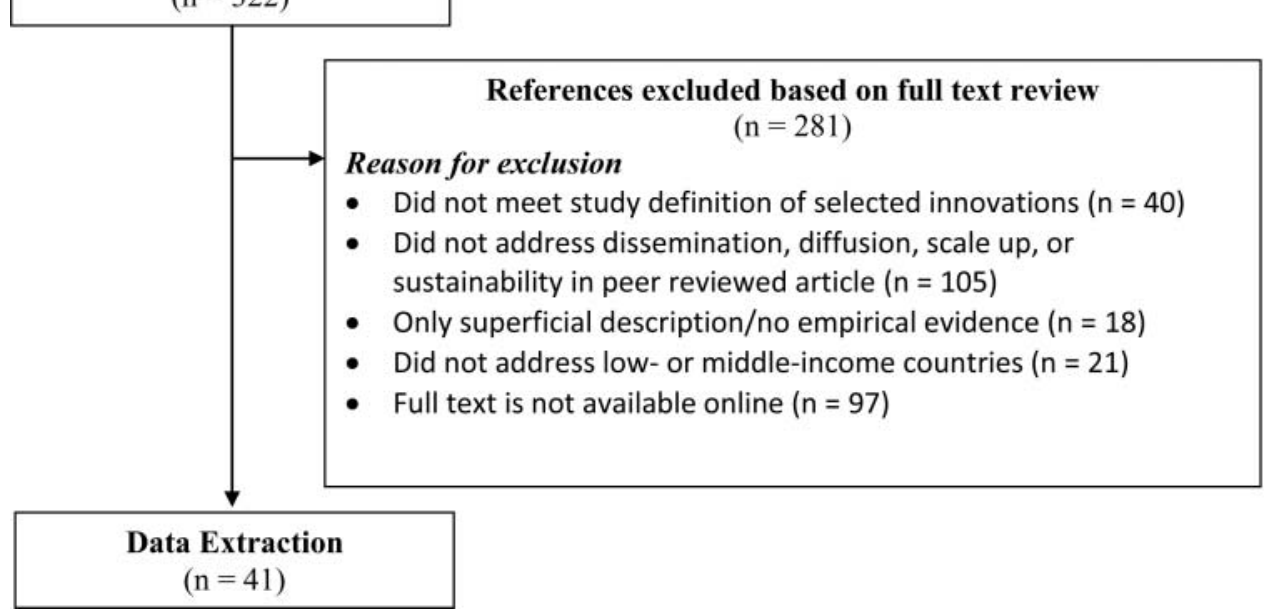

Figure 2 Selection of peer-reviewed literature. During the review, 4 additional papers not identified through the electronic search were obtained from the authors' files, resulting in a total of 45 peer-reviewed articles for review. Grey literature was obtained from the following Websites: WHO, United Nations Development Programme, United Nations Population Fund, United Nations Population Fund, the World Bank, the African Development Bank, the Inter-American Development Bank, the Asian Development Bank, United States Agency for International Development, Canadian International Development Agency, Department for International Development, Swedish International Development Agency, German Agency for Technical Cooperation, the Global Fund to Fight AIDS, Tuberculosis and Malaria, CARE, GAIN, Family Health International, Partners in Health, Management Sciences for Health and John Snow, Inc.

know that this particular intervention can solve that disease...then, why isn't this diffusing more?' You have to work from what consumers want. (Interview \#23)

In addition, the assessment component included examining environmental conditions that may promote or impede take up of the innovation. Key informants explained that such conditions include the political, regulatory, economic, social, cultural and technological environments. Relevant assessments may span multiple levels from the local to the global, as expressed by one key informant with regard to breastfeeding programmes:

Assessments occur at various levels. You have the assessment in the community to find out the beliefs and practices in the community. You have opinion leader research...to find out where you stand in terms of policies and their attitudes towards breastfeeding, and then stakeholder analysis. So we 
Table 2 Characteristics of peer-reviewed ( $\mathrm{n}=46$ sources) and grey literature ( $n=30$ sources)

\begin{tabular}{lc}
\hline Characteristic & $\begin{array}{l}\text { Number (percent) } \\
\text { of sources }\end{array}$ \\
\hline $\begin{array}{l}\text { Methodology* } \\
\text { Review of literature or existing }\end{array}$ & $25(33.3)$ \\
data & $25(33.3)$ \\
Case study & $14(18.6)$ \\
Qualitative interviews, focus & \\
groups, observations & $10(13.3)$ \\
Cross-sectional study & $11(14.6)$ \\
Pre-post intervention study & $1(1.3)$ \\
Simulation study & $1(1.3)$ \\
Randomised controlled trial & $1(1.3)$ \\
Mixed methods & $26(26.5)$ \\
Geographic region (as defined by the World Bank) & \\
Africa & $23(23.5)$ \\
East Asia and Pacific & $20(20.4)$ \\
South Asia & $15(15.3)$ \\
Latin America and Caribbean & $12(12.2)$ \\
General/None stated & \\
\hline *Percentages sum to more than $100 \%$ because some articles had \\
more than one methodology and/or had covered multiple regions.
\end{tabular}

have all those types of assessments at the very beginning. (Interview \#12)

\section{Innovate to fit with user receptivity}

This component included adapting the innovation to local context and preferences, so that receptive users would perceive the innovation as providing relative benefits in their specific context or environment. Adaptation involved making changes to the design and packaging of the innovation and was highlighted by key informants and in the literature. ${ }^{14}$ Involvement of stakeholders from user groups at this early stage facilitated matching between the innovation and user group receptivity. One key informant highlighted the importance of precise fit to a particular context in the case of Depo-Provera:
To activate this [the injection], it is very simple. A super simple device, it was not a hand-me-down. This was reengineered for the developing country. There was no developed country use for this technology at all. (Interview \#1)

Non-technical features of the innovation design and packaging were also noted as important. In the case of CHWs as an innovation, experts spoke about CHW task assignments, role definitions, and community perceptions as examples of design and packaging. Key informants highlighted how the visible benefits of using CHWs generated a perceived advantage for the innovation, which was critical to its fit with the community needs and wants, and subsequent take-up:

The community has to see CHWs as valuable. If they are doing something the community really values, it will work....In Nepal, CHWs were valued by the community mostly because [of] the Vitamin A program where the community health worker would give Vitamin A to kids. And that lowered mortality fast, and the communities really valued that. It raised the community health worker status quickly because they had Vitamin A. [Also], kids are dying of pneumonia and [if] the community health worker can save the kid by getting them to the right place and having medicines, then [the] community values that. It is very visible. (Interview \#11)

\section{Develop support}

This component referred to priming the environment to be supportive of increased use of the innovation. Developing support involved enhancing education as well as identifying and addressing resistance to the innovation. Key informants described resistance from groups that might suffer economic or political losses if the innovation became routine practice:

What you hear at the ministries of health is from people whose livelihood may be affected or whose turf or influence they think is being diminished. So, you know, nurses in Kenya right now...we are getting from the nursing association that we have unemployed nurses in Kenya. Why should we have community workers giving
Figure 3 Schematic of the AIDED model of scale-up.

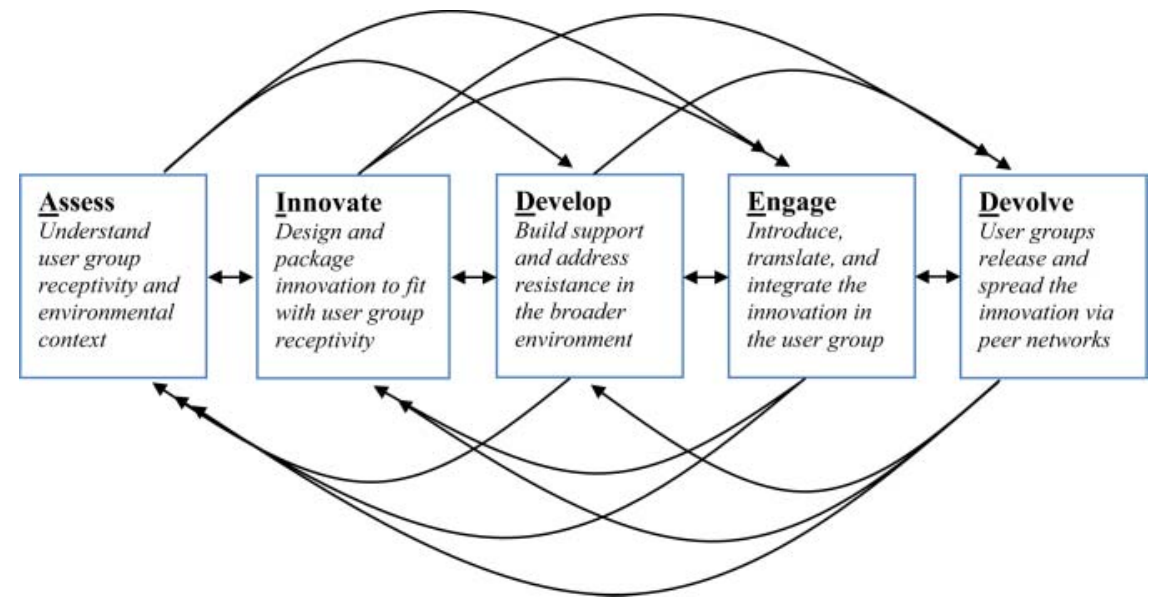


Depo injections ...the midwives and doctors will give similar answers and... it turns out to be a turf battle. (Interview \#14)

Involving these groups in assessment and innovation of components was also viewed as helpful to addressing resistance and building support. In adequate development of support and emerging resistance from stakeholders were common reasons cited for failure of scale-up efforts in the literature. ${ }^{16-19}$ Key informants emphasised the importance of strategic networking and collaboration in the development of political and economic support and support at the regional, national and global levels.

If you understood the political science and the political economy you'd see actually what I need to do is I need to target policy makers first. (Interview \#5)

One [effort is] focused at the policy level and working with decision makers...getting them the information that they need to then further promote or, if they are not already convinced, to help them be convinced. (Interview \#14)

Legal and regulatory action that supported the innovation also played a critical role according to key informants. For instance, in the case of exclusive breastfeeding, both key informants and the literature ${ }^{17} 19{ }^{20}$ noted the importance of legislation in providing paid maternity leave and curbing the marketing of substitutes for breast milk in several countries including Brazil:

Another important aspect that came...were the policies that were...elected by the government... [it was] decided to provide four months of paid maternity leave to formal working women....so ' 88 came this decision, this law, and also in 1988...an approval of the National Code of Marketing of Breast-Milk Substitute...also important for the continuation of the pro-breastfeeding campaign. (Interview \#22)

Understanding and addressing resistance was often accomplished by using data, in some cases from controlled trials funded in the country and in other cases through more non-traditional forms of data. For instance, the highly successful scale-up of CHWs in Pakistan involved building political support through evidence-based advocacy:

We spent a year collecting and generating local data from the district on perinatal mortality, its distribution, and causes of death. This more than anything was critical in focusing the attention of the local politicians and policy makers. [We] made several presentations to the Minister of Health and the Director General ...to persuade them of the importance of doing something and getting the buy-in from the program people. (Interview \#27)

Key informants underscored the role of economic incentives in developing support for the innovation and to propel scale-up. In the case of Depo-Provera, for instance, key informants discussed the importance of developing sufficient incentives to produce, sell and buy the product:

It's really not rocket science. You get a product; you put it in a box....If it's cheap enough, people will buy it. If it's too cheap, retailers won't stock it. Play with those two variables. The margins have to be attractive to those within the retail chain, but the end price has to be affordable to the consumer. (Interview \#7)

You promise [the manufacturer] more volume, asking them for lower margins. And the premise was that that drug now would go to the supply chain and end up at the frontline at between 30 and 50 cents, more or less. (Interview \#3)

Economic disincentives were noted as major sources of resistance, particularly in the areas of exclusive breastfeeding and use of CHWs, which were viewed by infant formula companies and clinicians, respectively, as crowding out their businesses. As a key informant said:

Despite their desire to breastfeed, [women] cannot do it because of economical reasons, social reasons...what kind of incentives should be given to women and families in order to increase the prevalence of choosing breastfeeding....It's a competition between different priorities that women go through. It's not that they don't want to. They have to do something else, to go to work. So the financial incentives would be important I think and that has not been done. (Interview \#8)

\section{Engage with user groups}

Engagement with user groups was viewed by key informants as occurring throughout the scale-up process and involved several necessary steps: (1) introduction of the innovation from outside the user group to inside the user group via boundary spanners, (2) translation of the innovation so that user groups could assimilate the new information and (3) integration of the innovation into the routine practices and social norms of the user group.

Introduction of the innovation, the first part of the engage component, referred to giving information about the innovation to the user group. Critical to the process, however, was that this introduction be accomplished by someone who had an essential, pre-existing role in the user group and who also has contact with people outside the potential user group, that is, someone who was a boundary-spanner. Translation, the second part of the engage component, was the process that made the new information clear and understandable to potential user groups, allowing it to be assimilated. Translation included the development of practical instructions, guides, blueprints and protocols that were comprehensible and relevant for the user group. In reflecting on the success factors in implementing the community health worker model in Nepal, one key 
informant described how people in the community collaborated in translation:

One of the reasons the manual was particularly good [was] ...we contracted with the literacy group and with UNICEF because they had the only good artists...And the three groups [the literacy group, UNICEF, and the Ministry] had to work together to produce the sort of communications...that worked with the CHWs. (Interview \#11)

Translation also included more subtle ways to contextualise or frame the innovation in a way that made it appealing to a larger number of people in the user group, such as describing the innovation using local idioms, stories or historical examples, or associating the innovation with important values or practices within the group.

\begin{abstract}
We realized that the best [health] counsellors were our cleaning ladies because they knew how to talk with the ladies. They knew the vocabulary, you know.... They were from the same neighbourhoods... They were more or less the age of the ladies... They were also mothers having the same problems. They talked to them very easily, not [acting as if] I am the boss here...I think it feels as if they were having a conversation. (Interview \#21)
\end{abstract}

In some examples, translation occurred via opinion leaders, such as in a reproductive health project in Afghanistan that disseminated information about contraception, including Depo, through religious leaders. The project avoided national religious policy debates but engaged religious leaders at the community level in discussions of the compatibility of contraception with teachings from the Quran. To accomplish this, the contraception was described not as a method of family planning, which would have been controversial, but instead was described as the best way to ensure women could breastfeed for 2 years, which was the duration prescribed in the Quran:

So the one-on-one discussions with the 37 mullahs in these 3 project areas... [the project manager] had these discussions and....and then all of them could agree that this was okay and it was consistent with Islam. (Interview \# 30)

Once religious leaders were convinced about the fit of the innovation with their values, these leaders then endorsed the use of contraception in the broader community.

So the mullahs as part of their organizing the community [said] here's how we're going to cover the 3,000 people in our community; we've laid out these plans. We'll make sure that these happen, and I will also talk with the men at Friday prayers about contraception. (Interview \#30)

The final aspect of the engage component, integration, referred to the embedding of the innovation in the routines and social norms of a user group. Integration was enabled by support through legislation, educational systems and changes to broader cultural norms beyond the immediate user group. For instance, a key informant described this kind of integration relative to breastfeeding in Brazil:

The behaviour change comes with this facilitation [by] the facilities that the woman finds in society. Instead of being sent out of the bus because she's breastfeeding or out of the health centre because she's breastfeeding, on the contrary, she is well received so this behaviour became normal. (Interview \#22)

In other instances, the innovation became part of what was taught and passed down to future generations, reflecting its integration into the routine practices of the user group and its sustainability over time. For instance, the CHWs in Nepal who grew too old to work passed the position down to their daughters. The position was viewed as an honour as it was believed to contribute to one's dharma for community service, ${ }^{21}$ which was thought to increase their acceptance in what they understood as the 'afterlife.'

Each of the communities wanted to be a quality midwife and to wear the brand of a Bidan Delima. There was an advertisement campaign, but much more so, it was a peer pressure, a sisterhood....Women stayed as CHWs for their career, and they ended up passing it down to their daughters. Now that is sustainability! (Interview \#10)

\section{Devolve efforts for spreading the innovation}

This component involved user groups' releasing and spreading the innovation for its re-introduction in new user groups within their peer networks. Key informants underscored the importance of peer networks in facilitating the process of release and spread to new user groups, suggesting that trust among the network members was essential, as described in these examples:

We're having huge success now in family planning in Africa by putting early adopters to counsel other women...I think we are seeing a real normative change in a whole bunch of communities in which we operate around family planning, IUDs, sterilization, injectables because, you know, you get women talking to other women. (Interview \#19)

Key informants noted that relinquishing control over the innovations' spread was ultimately necessary for full scale-up; however, doing so presented risks, particularly when the timeline for this transition occurred too soon. Key informants highlighted that 'some innovations have some negative and positive spinoffs' (Interview \#11). Positive spinoffs of spread included the take-up of innovation complements. For example, key informants described how increasing the use of CHWs also spread messages and services that they promoted, such as antenatal care, better hygiene, HIV testing and other public health efforts. In contrast, negative unintended 
consequences were also identified and some key informants voiced concerns that scale-up success should be determined based on comprehensive monitoring and evaluation efforts.

We need a balanced view and measurement impact because sometimes things [can have negative effects]. Think about the pneumonia vaccine. It is good, but it increases illness too maybe. If we can predict that ahead of time, we can plan for it and maybe lessen the negative impacts. (Interview \#11)

\section{Linkages among the components}

Although the model that emerged identified five common components, key informants cautioned that there was no single, definitive way to achieve effective scale-up in every context. Rather, they noted the 'myth of the magic bullet' (Interview \#23), which was summarised by explaining that 'these things are often very contextual, and there is n't a magic bullet. Just because something worked well in one country, doesn't mean it's going to work elsewhere' (Interview \#23). Hence, specific actions and strategies within each component remain context dependent.

\section{DISCUSSION}

We identified five distinct but interrelated components that comprised the AIDED model of scale-up for selected family health interventions in LMIC: assess the landscape, innovate to fit user receptivity, develop support, engage with user groups and devolve efforts for spreading the innovation. Critical to implementing such an approach is the recognition that the progression through these components may be non-linear and involve multiple feedback loops, which can necessitate reversions to previous components. The model further indicates that successful scale-up is not fully under the control of the innovator, donor or implementer but rather grows organically out of a deep understanding of and engagement with user groups and their environmental contexts.

Although the concepts that emerged from the in-depth interviews and from the systematic literature review were largely consistent, important distinctions between the two data sources were also apparent. For instance, we gathered more evidence about the component of 'assess' from in-depth interviews than from empirical literature. Interviews highlighted the multiple levels of assessment undertaken in successful scale-up efforts including the assessment of community receptivity, political support, economic viability, and technical feasibility, whereas studies in the empirical literature mentioned assessment in general terms or of only a single type (eg, community needs assessment). Some empirical studies reported only postlaunch phases of the intervention and therefore did not include information about prelaunch assessment, perhaps due to space constraints or the perceived lack of novelty of such information. We also gathered more evidence about the devolve component from the in-depth interviews than from empirical papers, which often reported data to demonstrate widespread uptake but with more limited description of the specific processes used. Additionally, the in-depth interviews produced richer detail about failures to scale up with views about the reasons for failure, which were less well documented in the literature. The distinctions highlight the importance of triangulation, ${ }^{8}$ that is, using multiple sources of data to understand complex systems issues and underscore the limitations of empirical literature, which may omit key insights about how scale-up has been achieved and underemphasise null findings and failures in scale-up.

Despite the widespread agreement about recurrent themes related to the components of the AIDED model, some heterogeneity existed. For instance, interviewees differed in the degree to which they believed that scale-up success required private market strategies. Some thought that adequate ongoing government and foundation support was sufficient to promote widespread take-up while others viewed a private market-based incentive system to be essential. Still others highlighted that the importance of private market versus public sector involvement depended on the type of innovation. Depo-Provera, for instance, was viewed by some as being conducive to market-based spread whereas the community health worker model was believed to require ongoing public sector support to be effective as an integral part of the public health system. A second area of heterogeneity across the in-depth interviews was the degree to which successful scale-up initiatives followed a top-down approach in which ministries of health and high-level decision makers promoted the innovation or a bottom-up approach in which the user community drove the adoption. Although the interviewees reflected on the importance of support among all levels, views differed in the ordering of attaining that support, underscoring our conclusion that the process is non-linear and may unfold in diverse sequences without a single path to successful scale-up.

The findings suggest that the process of scale up is dependent on a complex adaptive system, which includes several interlocking parts, multiple feedback loops and many potential pathways to success. The emergent and somewhat unpredictable nature of complex adaptive systems has several implications for policymakers, practitioners and researchers. First, real-time, valid information flow across the system is essential to effective scale-up. Because actors in the system adapt based on what they understand as environmental conditions, misinformation can create suboptimal situations quickly. Therefore, investments in the data infrastructure and the relationships that underpin valid and reliable information flow are paramount. Second, the achievement of widespread innovation use is the result of a multifactorial process and cannot be attributed simply to specific, planned actions. Because there are multiple paths to the same outcome, 


\begin{tabular}{|c|c|c|}
\hline Component & Activities within component & Outputs from activities \\
\hline \multirow[t]{3}{*}{ ASSESS } & 1. Landscape assessment & $\begin{array}{l}\text { 1. Mapping of environmental conditions that would support or be } \\
\text { barriers to use of the innovation in its pre-existing form has been } \\
\text { created }\end{array}$ \\
\hline & 2. User group needs assessment & $\begin{array}{l}\text { 2. List of prioritized needs and wants of the index user groups has been } \\
\text { compiled and reviewed with members of index user groups; : } \\
\text { understanding of user group's receptivity to the innovation is clear }\end{array}$ \\
\hline & 3. Readiness for change assessment & $\begin{array}{l}\text { 3. Measure of readiness for change in the area of the innovation has been } \\
\text { developed and evaluated }\end{array}$ \\
\hline \multirow[t]{2}{*}{ INNOVATE } & $\begin{array}{l}\text { 1. Tailor design and packaging of innovation } \\
\text { to index user groups' needs/wants }\end{array}$ & $\begin{array}{l}\text { 1. Well-tailored innovation has met index user groups' needs/wants } \\
\text { identified in assess component; innovation has been adapted to fit the } \\
\text { receptivity of the user group }\end{array}$ \\
\hline & $\begin{array}{l}\text { 2. Test market (e.g., conduct focus groups of } \\
\text { index user group members to determine } \\
\text { 'fit' and willingness to pay) }\end{array}$ & 2. Test marketing results have been synthesized for review \\
\hline \multirow[t]{4}{*}{ DEVELOP } & $\begin{array}{l}\text { 1. Cultivate support among high-level } \\
\text { champions }\end{array}$ & 1. High-level champions have manifested their support for the innovation \\
\hline & 2. Promote policy reforms & 2. Needed policy reforms have been enacted \\
\hline & $\begin{array}{l}\text { 3. Facilitate knowledge sharing and } \\
\text { technology transfer }\end{array}$ & $\begin{array}{l}\text { 3. Mechanisms for knowledge sharing and technology transfer have been } \\
\text { established or needed knowledge/technology has been acquired }\end{array}$ \\
\hline & $\begin{array}{l}\text { 4. Employ social marketing techniques to } \\
\text { foster new norms }\end{array}$ & $\begin{array}{l}\text { 4. Social marketing campaigns have leveraged cultural norms to build } \\
\text { support for the innovation }\end{array}$ \\
\hline \multirow[t]{6}{*}{ ENGAGE } & $\begin{array}{l}\text { 1. Identify boundary spanners and introduce } \\
\text { them to innovation }\end{array}$ & $\begin{array}{l}\text { 1. Boundary spanners with pre-existing roles within the user groups have } \\
\text { been identified and are introducing innovation in index user groups }\end{array}$ \\
\hline & $\begin{array}{l}\text { 2. Develop tools and collaborations to assist } \\
\text { in translation of the innovation within } \\
\text { index user groups }\end{array}$ & $\begin{array}{l}\text { 2. Tools for translation, developed in collaboration with people in index } \\
\text { user groups, exist }\end{array}$ \\
\hline & Inside index user groups: & \\
\hline & $\begin{array}{l}\text { 3. Translate innovation to facilitate } \\
\text { integration into index user groups' norms }\end{array}$ & $\begin{array}{l}\text { 3. Innovation has been translated into terms that are accessible, familiar, } \\
\text { and attractive to index user groups }\end{array}$ \\
\hline & $\begin{array}{l}\text { 4. Integrate innovation into index user } \\
\text { groups' norms }\end{array}$ & $\begin{array}{l}\text { 4. Index user groups feel ownership over the implementation of the } \\
\text { innovation }\end{array}$ \\
\hline & $\begin{array}{l}\text { 5. Encourage adaptation and replication of } \\
\text { innovation within index user group }\end{array}$ & $\begin{array}{l}\text { 5. Adapted and replicated versions of the originally introduced innovation } \\
\text { have emerged from index user groups }\end{array}$ \\
\hline \multirow[t]{3}{*}{ DEVOLVE } & $\begin{array}{l}\text { 1. Map social networks of index user groups } \\
\text { along which innovation may spread }\end{array}$ & $\begin{array}{l}\text { 1. Social network mapping (to use as basis for determining which other } \\
\text { user groups to monitor for subsequent knowledge/use of innovation) }\end{array}$ \\
\hline & $\begin{array}{l}\text { 2. Facilitate movement of innovation across } \\
\text { the boundary (from inside to outside) of } \\
\text { index user groups }\end{array}$ & $\begin{array}{l}\text { 2. Innovation has been shared by members of index user groups with } \\
\text { external parties who share similar receptivity to the innovation }\end{array}$ \\
\hline & $\begin{array}{l}\text { 3. Introduce innovation to boundary } \\
\text { spanners from other (non-index) user } \\
\text { groups }\end{array}$ & $\begin{array}{l}\text { 3. Boundary spanners from other (non-index) user groups have been } \\
\text { exposed to the innovation }\end{array}$ \\
\hline
\end{tabular}

Figure 4 AIDED model activities and outputs. Note: The model takes as its starting point that an innovation exists in some form, and addresses the question of how to scale up use of that existing innovation.

system interventions that include coordination of multiple levels of action (eg, global, national, local) are most likely to produce successful scale-up. Cost-effective management information systems are required for providing the level of coordination needed. Last, because the full outcomes are somewhat unpredictable in complex adaptive systems, it is important to anticipate unintended negative consequences that may emerge and to develop contingency plans for these potential occurrences. Furthermore, careful attention to incentives and accountability systems to limit negative consequences is essential to ethical and effective efforts to disseminate and diffuse innovations.

How does the AIDED model add to existing frameworks for scale-up? Several experts have described important frameworks for scale-up in low-income countries ${ }^{4} 72223$ and in higher-income settings. ${ }^{5}{ }^{24-26}$ Although frameworks differ in their emphasis and comprehensiveness, together these provide a list of domains of variables that may be important for scale-up. These include: (1) attributes of the innovation, largely drawn from Rogers' work suggesting innovations are more likely to spread if they have relative advantage as perceived by users, are easy to understand and use, are compatible with current practices, can be tested before large-scale adoption and have observable results; (2) attributes of the resource system and implementers (ie, the systems that produces and implement the innovation) such as their credibility, understanding of the environment, technical skills and management capacity; (3) attributes of the adopting community or user groups including their perceptions of need, readiness to change, capacity to absorb innovations and engagement in the process, and (4) attributes of the socio-political and economic environment including how conducive it is to 
fostering spread. Some frameworks have also highlighted the importance of the chosen delivery strategy ${ }^{4}$ including tailoring the distribution efforts to local situations and using existing social networks ${ }^{4525}$ to promote spread. In contrast to providing a list of important attributes, the AIDED model both provides a theory of the interrelated actions important for scale-up and organises them into five concrete, clearly defined components. Concepts from existing frameworks, such as relative advantage as perceived by user groups and the role of the environment, pertain to the AIDED model. Our findings, however, provide practical guidance for how one might plan and implement scale-up efforts. In addition, our findings highlight the interactions among the different components of scale-up, suggesting that multiple paths may lead to widespread take-up of innovations.

To facilitate the practical application of the AIDED model, we developed a template of activities, outputs, outcomes, outcome indicators and means of measuring progress for each of the five components (figures 4 and 5) as well as a set of flow charts illustrating the application of the AIDED model (see the appendix, figures A1-A5). These matrices and flow charts facilitate the application of the AIDED model in implementation and evaluation of efforts to disseminate, diffuse and scale-up innovations in low-income settings. Over time, such a tool could be refined with application and validated to ensure that the activities identified are those associated with more successful scale-up.

Our findings should be interpreted in the light of several limitations. The inductive approach used to construct the AIDED model did not allow for simultaneous empirical testing of the model. Future research is needed to test the AIDED model in diverse contexts. Additionally, many of the interviewees were affiliated with the BMGF. This foundation is managing $\$ 1.5$ billion in family health programmes and has a highly diverse staff with deep experience and expertise in this area including prior to their affiliation with the BMGF. Nevertheless, this may limit the transferability of our findings to other contexts. Furthermore, only one article reported a randomised controlled trial, and most studies were observational or qualitative in nature, limiting the ability to make causal inferences. The literature may also have publication bias ${ }^{27}$ in which negative studies are underrepresented, and interviews may have social desirability bias, ${ }^{28}$ in which participants may have misrepresented their experiences in order to provide desirable answers. Nonetheless, we did find cases of unsuccessful scale-up in the literature, and we probed intentionally to elicit both positive and negative experiences from key informants in order to minimise bias. Last, the AIDED model did not

\begin{tabular}{|c|c|c|c|}
\hline Component & Outcome of component & Outcome indicator & Means of measuring outcome indicator \\
\hline ASSESS & $\begin{array}{l}\text { Identification of changes needed in (a) } \\
\text { the innovation itself, (b) the } \\
\text { environment, or (c) the user group in } \\
\text { order to support use of the innovation } \\
\text { in index user groups ( ( a) is addressed } \\
\text { in innovate component, (b) in develop } \\
\text { component, and (c) in engage } \\
\text { component) }\end{array}$ & $\begin{array}{l}\text { Documentation of changes } \\
\text { needed in innovation, } \\
\text { environmental conditions, and } \\
\text { user groups in order to support } \\
\text { use of the innovation in index } \\
\text { user groups }\end{array}$ & Synthesis report of the assessments completed \\
\hline INNOVATE & $\begin{array}{l}\text { Achievement of acceptable threshold } \\
\text { of fit between innovation and index } \\
\text { user groups }\end{array}$ & $\begin{array}{l}\text { Degree of 'fit' of innovation to } \\
\text { index user groups }\end{array}$ & $\begin{array}{l}\text { Results from test marketing (focus groups, } \\
\text { willingness to pay studies, market analysis) }\end{array}$ \\
\hline DEVELOP & $\begin{array}{l}\text { Barriers to the innovation have been } \\
\text { mitigated and support for the } \\
\text { innovation has been secured in the } \\
\text { political, regulatory, economic, socio- } \\
\text { cultural, technological, and knowledge } \\
\text { environments of index user groups }\end{array}$ & $\begin{array}{l}\text { Degree of support for innovation } \\
\text { in political, regulatory, } \\
\text { economic, socio-cultural, } \\
\text { technological, and knowledge } \\
\text { environments }\end{array}$ & $\begin{array}{l}\text { Required environmental changes identified in } \\
\text { the assess component have all been } \\
\text { addressed; Stakeholder analysis; Follow-up } \\
\text { landscape assessment to identify any new } \\
\text { barriers that have emerged }\end{array}$ \\
\hline ENGAGE & $\begin{array}{l}\text { a. Innovation is in use by a target } \\
\text { percentage in index user groups } \\
\text { (i.e., number of users divided by the } \\
\text { total members in index user groups) } \\
\text { b. Innovation is perceived as 'standard' } \\
\text { by target percentage in index user } \\
\text { groups } \\
\text { c. Innovation is evolving to be more } \\
\text { compatible with local social norms } \\
\text { due to adaptation efforts by index } \\
\text { user groups }\end{array}$ & $\begin{array}{l}\text { a. Extent of knowledge, } \\
\text { perceptions, and use of } \\
\text { innovation in index user groups } \\
\text { b. Degree to which innovation is } \\
\text { perceived as 'standard' by } \\
\text { index user groups } \\
\text { c. Degree to which adapted } \\
\text { innovations are faithful to } \\
\text { originally introduced } \\
\text { innovation (in impact) }\end{array}$ & $\begin{array}{l}\text { Primary data collection in index user groups } \\
\text { regarding use and perceptions of innovation } \\
\text { (could include surveys, in-depth interviews, } \\
\text { focus groups, participant observation) }\end{array}$ \\
\hline \multirow[t]{2}{*}{ DEVOLVE } & $\begin{array}{l}\text { a. Index user groups have shared the } \\
\text { innovation with other user groups }\end{array}$ & $\begin{array}{l}\text { a. Level of awareness of } \\
\text { innovation in larger set of user } \\
\text { groups }\end{array}$ & $\begin{array}{l}\text { Primary data collection in index user group } \\
\text { regarding awareness and use of innovation } \\
\text { (e.g., surveys, in-depth interviews, focus } \\
\text { groups, participant observation) }\end{array}$ \\
\hline & $\begin{array}{l}\text { b. Innovation is in use by target } \\
\text { percentage in user groups beyond } \\
\text { index user groups }\end{array}$ & $\begin{array}{l}\text { b. Extent of knowledge, } \\
\text { perceptions, and usage of } \\
\text { innovation in larger set of user } \\
\text { groups }\end{array}$ & \\
\hline $\begin{array}{l}\text { OVERALL } \\
\text { AIDED } \\
\text { MODEL }\end{array}$ & $\begin{array}{l}\text { Intended health impact is realized in } \\
\text { the target population }\end{array}$ & $\begin{array}{l}\text { Change in relevant target } \\
\text { population health indicators }\end{array}$ & Population surveys, surveillance data \\
\hline
\end{tabular}

Figure 5 AIDED model outcome measures. 
address long term, sustained use of innovations that are successfully scaled up. This will require longitudinal research examining contrasting levels of success sustaining the scaled-up innovations in different settings.

In sum, we identified five key components, which our findings suggest interact in a complex adaptive system to explain the process of widespread take up and anticipate the success of scale up efforts. Paradoxically, complex adaptive systems are at once capable of fast and sweeping changes and homeostatic. Despite substantial changes that can occur within a complex adaptive system, each part of the system responds to disturbances in such a way that the system can maintain the status quo. We identified in this paper several leverage points for launching substantial changes in large systems. Nevertheless, recognising the fundamental complexity of the scale-up process, funders and innovators alike will require flexible strategies of assessment, innovation, development, engagement and devolution to enable effective change in the use of family health innovations in LMIC.

Contributors EHB conceptualised and designed the study, conducted and monitored data collection for the literature review and interview components, analysed the data and drafted and revised the paper. She is the guarantor. LAC conceptualised and designed the study, conducted and monitored data collection for the interview component, analysed the data and drafted and revised the paper. LT managed all aspects of the study, conducted data collection, participated in data analysis and drafting and revising the paper. SWP participated in data analysis for the literature review and interviews and drafted and revised the paper. KTS participated in data analysis. CY participated in the literature search and related analyses. AF conducted data collection and participated in data analysis. DM coordinated the literature search and interview components, participated in data analysis for the literature review and interviews. DKC contributed to project management, writing and revising the paper. DB contributed to data analysis for the interview component. RPE participated in data analysis for the literature review and writing and revising the paper.

Funding This work was supported by the Bill and Melinda Gates Foundation, grant number 18542.

Competing interests None.

Provenance and peer review Not commissioned; externally peer reviewed.

Data Sharing Statement There are no additional unpublished data available to share.

\section{REFERENCES}

1. Clifton $\mathrm{D}$, Clifton $\mathrm{T}$, Kaneda $\mathrm{D}$, et al. Family planning worldwide: 2008 data sheet. Washington, DC: Population Reference Bureau, 2008.

2. Childinfo: Statistics by area/child nutrition (Internet). New York: UNICEF, 2011; cited 9 Jan 2012. http://www.childinfo.org/ breastfeeding_progress.html
3. World Health Statistics 2011 (Internet). Geneva, Switzerland: World Health Organization, 2011; cited 3 Jan 2012. http://www.who.int/ whosis/whostat/EN_WHS2011_Full.pdf

4. Yamey G. Scaling up global health interventions: a proposed framework for success. PLOS Med 2011;8.

5. Greenhalgh T, Robert G, MacFarlane F, et al. Diffusion of innovations in service organizations: systematic review and recommendations. Milbank Q 2004;82:581-629.

6. Rogers EM. Diffusion of innovations. 4th edn. New York: Free Press, 1995.

7. Simmons R, Fajans $\mathrm{P}$, Ghiron L, eds. Scaling up health service delivery: from pilot innovations to policies and programmes. Geneva: World Health Organization, 2007.

8. Patton MQ. Qualitative research and evaluation methods. Thousand Oaks: Sage Publications, 2002.

9. Sofaer S. Qualitative methods: what are they and why use them? Health Serv Res 1999;34:1101-18.

10. Pope C, Mays N. Reaching the parts other methods cannot reach: an introduction to qualitative methods in health and health services research. BMJ 1995;311:42-5.

11. Glaser B, Strauss A. The discovery of grounded theory. Hawthorne, NY: Aldine Publishing Company, 1967.

12. Mays N, Pope C. Rigour and qualitative reserach. BMJ 1995;311:109-12.

13. Mays N, Pope C. Qualitative research in health care: analysing qualitative data. BMJ 2000;320:50-2.

14. Huber D, Saeedi N, Samadi AK. Achieving success with family planning in rural Afghanistan. Bull World Health Organ 2010;88:227-31.

15. Fajans $P$, Nguyen TT, Whittaker A, et al. Strategic choices in scaling up: introducing injectable contraception and improving quality of care in viet nam. In: Simmons R, Fajans P, Ghiron L, eds. Geneva: World Health Organization, 2007:31-52.

16. Levy R, Agarwal D, Miller P. Expanding access and demand for DMPA in Uttar Pradesh, Jharkhand and Uttarkhand. USAID evaluation report. Washington, DC: USAID, 2009.

17. Rea MF. A review of breastfeeding in Brazil and how the country has reached ten months' breastfeeding duration. (A transicao nutritcional e a epidemiologia da obesidade na america latina). Cadernos Saude Publ 2003;19(Suplemento 1):S37-45.

18. Consolidated report of six-country review of breastfeeding programmes. New York: UNICEF, 2010.

19. Learning from large-scale community-based programmes to improve breastfeeding practices. Geneva, Switzerland: World Health Organization, 2008

20. Jelliffe DB, Jelliffe EFP, eds. Programmes to promote breastfeeding. Oxford, UK: Oxford University Press, 1988.

21. Glenton C, Scheel IB, Pradhan S, et al. The female community health volunteer programme in Nepal: decision makers' perceptions of volunteerism, payment and other incentives. Soc Sci Med 2010;70:1920-7.

22. Shiffman J. HIV/AIDS and the rest of the global health agenda. Bull World Health Organ 2006;84:923.

23. Atun R, de Jongh $\mathrm{T}$, Secci $\mathrm{F}$, et al. Integration of targeted health interventions into health systems: a conceptual framework for analysis. Health Policy Plann 2010;25:104-11.

24. Yuan CT, Nembhard IM, Stern AF, et al. Blueprint for dissemination of evidence-based practices. Issue Brief (Commonw Fund) 2010;86:1-16.

25. Rogers EM. Diffusion of innovations. New York: Free Press, 1995.

26. McCannon CJ, Perla RJ. Learning networks for sustainable, large-scale improvement. Jt Comm J Qual Patient Saf 2009;35:286-91.

27. Sackett DL. Bias in analytic research. J Chronic Dis 1979;32: $51-63$.

28. Sudman S, Bradburn NM. Thinking about answers: the application of cognitive processes to survey methodology. San Francisco: Jossey-Bass Publishers, 1996. 